
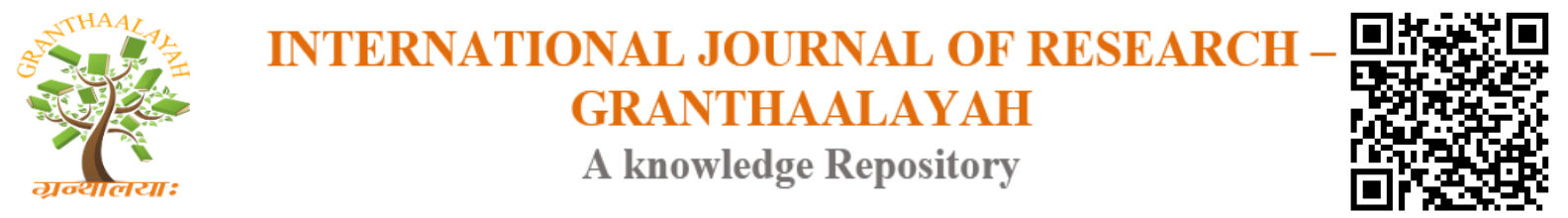

Science

\title{
AWARENESS, ATTITUDE AND PRACTICE TOWARDS HALITOSIS- A CASE STUDY AT COLLAGE OF HEALTH SCIENCE AND TECHNOLOGY JAHUN, JIGAWA STATE NIGERIA
}

\author{
Sambo Haruna Aliyu ${ }^{1}$, Yusuf Zakariyya Adam ${ }^{2}$, Rabiu Salisu Hassan ${ }^{1}$, Sani Hashim ${ }^{3}$ \\ ${ }^{1}$ Department of General Studies, Collage of Health Science and Technology Jahun Jigawa State \\ Nigeria \\ ${ }^{2}$ Department of Dental Health Sciences, Collage of Health Science and Technology Jahun \\ Jigawa State Nigeria \\ ${ }^{3}$ Department of Environmental Health Sciences, Collage of Health Science And Technology \\ Jahun Jigawa State Nigeria
}

\begin{abstract}
Globally halitosis has been associated with stigma, social insecurity, anxiety, depression and symptoms of obsessive disorder among those affected. Research has shown that there is no universal agreement about what diagnosis criteria and what detection method should be used to define which individual have halitosis and which do not have. The study was conducted to assess awareness attitude and practice toward halitosis among students of collage of health sciences and technology Jahun Jigawa state. The study design adopted was a descriptive and cross sectional type. 305 students were randomly selected from different departments which were broken down into different strata's. Structured questionnaire were employed as tool for data collection containing questions on the awareness, attitude and practices of the respondents towards halitosis. The results depicts that about $68.9 \%$ of the respondent were aware of the condition Halitosis. Majority of the respondents also agreed that poor oral hygiene can lead to halitosis while $44.3 \%$ were of the opinion that halitosis can lead to illness unspecified. On the attitude towards people with halitosis, majority $(60.7 \%)$ ascertain that they do not isolate people suffering from the condition. Also on the practice of respondents towards the condition, 75.4\% chew gum and sweet to manage halitosis. The study revealed that respondents were aware of halitosis as well as measures towards managing the condition. The study therefore recommends that brushing of teeth regularly and visiting dental clinics should be encouraged as means of curbing halitosis in the community.
\end{abstract}

Keywords: Breath; Behavior; Condition; Depression; Odour; Psychological.

Cite This Article: Sambo Haruna Aliyu, Yusuf Zakariyya Adam, Rabiu Salisu Hassan, and Sani Hashim. (2018). "AWARENESS, ATTITUDE AND PRACTICE TOWARDS HALITOSIS- A CASE STUDY AT COLLAGE OF HEALTH SCIENCE AND TECHNOLOGY JAHUN, JIGAWA STATE NIGERIA." International Journal of Research - Granthaalayah, 6(4), 72-79. https://doi.org/10.29121/granthaalayah.v6.i4.2018.1477. 


\section{Introduction}

Globally halitosis also known as "fetor Oris" has been associated with stigma, social insecurity, anxiety, depression and symptoms of obsessive disorder among those affected (Asiya et al., 2012; Kapoor et al., 2016). Historically, the earliest known mention of bad breath occurred in ancient Egypt where detailed recipes for making toothpaste were prepared before arriving at the final product. However, Hippocratic medicine advocated a mouth wash of red wine and species to cure bad breath while the ancient roman physician Pliny wrote about methods that can be employed to sweeten the breath. (Eggert et al., 2012). In the present day, bad breath is one of the biggest social taboos. A study revealed that an estimate of $\$ 1$ billion is spent annually by consumers in the United States for the purchase of deodorant-type mouth (oral) rinses, mint, and related over-the-counterproducts all aimed towards the avoidance of bad breath (Quirynen et al., 2012). However all these methods have been tagged to be short term and aimed at concealing the odor for a while. The problem of Bad breath has evolved over time to become an important social taboo and can cause unease not only related to health but also psychologically which in turn leads to social and personal isolation (Sanz et al., 2001). In addition, halitosis has been associated with the following impacts as classified below:

\subsection{Social Impacts Which Includes}

- Impact on marriage

- Impact on love life

- Impact on friend ship

- Impact on daily social interaction

- Reaction of other people to halitosis sufferers.

- impact on schooling and career

- impact on employment and employability

- Abuse of oral care products

\subsection{Psychological Impacts Which Includes}

- $\quad$ self-image, self-esteem, self-confidence

- Happiness

- Social phobia

- Depression

- $\quad$ suicidal intents

- Loneliness

- $\quad$ Substances abuse (Krespi, 2001; Ashrin, 2003; Shipman, 2006, Elias, 2007)

The theoretical framework of this study was based on the specific and the none specific theory. The specific theory states that just a few 'single' are etiological and capable of causing mal odor; their presence slowly will explain mal odor while the none specific theory state that many species most being strict an aerobes which have the ability to bio_transform substrates in to volatile sulphur compound and that many group can therefore substitute for other; there is single causative species. It's probably the microbial load that best predict the total level of bio transforming enzymes and (bio transforming micro environments) found in the mouth (cully et al., 2008). 
Different researchers have reported that it is often difficult for one to smell own breath/odor which is due to acclimatization, although many people with bad breath are able to detect. The argument has been that self-evaluation of halitosis has not been easy because of the preconceived notion of how bad we think it should be while some people assumed that they have bad breath because of bad taste, however bad taste is considered a poor indicator (Eli et al., 2001).

According to Cortelli et al., 2008 lack of universal agreement about what diagnosis criteria or tool and what detection method should be employed to term which individual have halitosis and which do not, has directed people to resort to self-reported estimate. This practice has contributed to a large variability on reported cases of halitosis. The management of halitosis can be based on physical or chemical means to decrease the number of bacteria thereby masking the smell odor while the use of tobacco has been strongly disapproved. Reports has shown that there is tentative benefit from tongue cleaning, treatment of gum diseases ,cavities of the teeth, diseases outside the oral cavity and counselling (Vanders,2010; Kapoor 2016). According to Thrane 2009, proper oral hygiene is the key for fresh breath while stressing that regular tooth brushing, Flossing and mouth rinsing with a mouth wash should all be part of the oral hygiene routine for a fresh breath and healthy teeth.

\section{Materials and Methods}

The study design was a descriptive and cross-sectional type. Using the krejcie and Morgan formula of 1970 an approximate sample size of 305 was deduced. Purposive sampling was used to select all Departments in the school which comprises of Community Health Department, Environmental Health Department, Medical Health Record Department, Medical Laboratory Department, Pharmacy Department and Dental Health Sciences Department making a total of six (6) departments. This will ensure full representation. A range of methods employed for the collection of data included questionnaire survey which targeted 305 stratified randomly selected students and the number of respondents to be picked from each strata (which in these case was the department of the respondents) were obtained based on proportion. With the help of research assistant Interviewer-administered questionnaires was used to collect quantitative data from sampled students. The questionnaire comprised of structured questions having both closed and open ended questions. The questionnaire was used to collect information from respondents on their awareness, attitude and practice towards halitosis in the study area.

\section{Results}

Table 1 shows results on the demographic characteristics of respondents. The table depicts that majority of the respondents where females with $62.3 \%$ while males accounted for $37.7 \%$. On the age of the respondents, those within the age bracket of 18-22years were the majority with $57.4 \%$, 23-27years accounted for $36.1 \%$, while those in the age bracket of $28-32$ years accounted for $6.5 \%$ of the respondents. The results further depicts that majority of the respondents were single with $88.5 \%$ while only $11.5 \%$ were married. Also on the level of education, the table depicts that $39.3 \%$ of the respondents had a diploma, $34.4 \%$ were certificate holders while HND holders accounted for $26.3 \%$ of the respondents. 
Results presented in Table 2 shows the Percentage Distribution of Respondent on Awareness of Halitosis. The table reveals that majority of the respondents were aware of the condition with $68.9 \%$ while $31.1 \%$ were not aware of the condition halitosis. Also a larger percentage of the respondents are aware that unclean teeth can cause halitosis which in turn can lead to social and psychological problems as accounted by $90.2 \%$ of the respondents. On the awareness on other illness that can lead to halitosis, $55.7 \%$ denied having knowledge on any of these illness while $44.3 \%$ ascertained having knowledge on the illness.

Table 3 shows results on the attitude of respondents towards halitosis, the table reveals that $60.7 \%$ of the respondents do not isolate people with halitosis, while $39.3 \%$ ascertained that they find it difficult to associate with people suffering from the condition. Also a large percentage do not feel comfortable when they do not brush their teeth in the morning while $59.1 \%$ of the respondents confirmed that they are comfortable with themselves even without brushing their teeth in the morning. Also the table further reveals that majority have never experienced any oral abnormality while 27.9 had experienced different abnormalities at one time in their lives.

Table 4 depicts the Percentage Distribution of Respondents on Practice towards Halitosis. The table reveals that $60.7 \%$ of the respondents do take substances that cause bad breath, while $39.3 \%$ denied the intake of substances that cause bad breath. On the use of substances to m manage the condition, majority $75.4 \%$ confirmed the use of substances while a small portion use not substances to manage the condition. Also the table depicts that a large percentage of the respondents $90.2 \%$ do brush their teeth twice daily while only $9.8 \%$ denied the brushing of teeth twice daily. The result also reveals that only a small portion of the respondents $13.1 \%$ do no visit a dentist at least twice a year.

Table 1: Demographic characteristics of respondents $(n=305)$

\begin{tabular}{|l|l|l|l|}
\hline & Variable & Frequency & Percentage (\%) \\
\hline Gender & Male & 115 & 37.7 \\
& Female & 190 & 62.3 \\
\hline Age & 18-22years & 175 & 57.4 \\
& 23-27years & 110 & 36.1 \\
& 28-32years & 20 & 6.5 \\
\hline Marital Status & Single & 270 & 88.5 \\
& Married & 35 & 11.5 \\
\hline Educational Level & Certificate & 105 & 34.4 \\
& Diploma & 120 & 39.3 \\
& HND & 80 & 26.3 \\
& Total & $\mathbf{3 0 5}$ & $\mathbf{1 0 0}$ \\
\hline
\end{tabular}

Source: primary data

Table 2: Percentage Distribution of Respondent on Awareness of Halitosis $(n=305)$

\begin{tabular}{|l|l|l|l|}
\hline S/n & Variable & Yes (\%) & No (\%) \\
\hline 1. & Have you heard about the condition halitosis? & $\begin{array}{l}210 \\
(68.9)\end{array}$ & $95(31.1)$ \\
\hline 2. & $\begin{array}{l}\text { Do you think halitosis/bad breath can lead to social and } \\
\text { psychological problem? }\end{array}$ & $275(90.2)$ & $30(9.8)$ \\
\hline
\end{tabular}




\begin{tabular}{|l|l|l|l|}
\hline 3. & Do you know unclean teeth can lead to halitosis? & $275(90.2)$ & $30(9.8)$ \\
\hline 4. & Do you know any other illness that can lead to halitosis? & $135(44.3)$ & $170(55.7)$ \\
\hline
\end{tabular}

Source: primary data

Table 3: Percentage Distribution of Respondents on Attitude towards Halitosis $(n=305)$

\begin{tabular}{|l|l|l|l|}
\hline S/n & Variable & Yes (\%) & No (\%) \\
\hline 1. & $\begin{array}{l}\text { Do you isolate person suffering from bad breath to } \\
\text { interact with you? }\end{array}$ & $120(39.3)$ & $185(60.7)$ \\
\hline 2. & $\begin{array}{l}\text { Do you feel uncomfortable whenever you wake up and } \\
\text { have not cleaned your mouth }\end{array}$ & $180(59.1)$ & $125(40.9)$ \\
\hline 3. & Have you suffered from any oral abnormalities before? & $85(27.9)$ & $220(72.1)$ \\
\hline
\end{tabular}

\section{Source: primary data}

Table 4: Percentage Distribution of Respondents on Practice towards Halitosis $(n=305)$

\begin{tabular}{|l|l|l|l|}
\hline S/n & Variable & Yes (\%) & No (\%) \\
\hline 1. & $\begin{array}{l}\text { Do you take substances or foods that can cause bad } \\
\text { breath? }\end{array}$ & $185(60.7)$ & $120(39.3)$ \\
\hline 2. & $\begin{array}{l}\text { Do you swallow, chew, or spray substances that helps } \\
\text { to manage the condition of halitosis? }\end{array}$ & $230(75.4)$ & $75(24.6)$ \\
\hline 3. & $\begin{array}{l}\text { Do you brush your teeth twice daily and flossing } \\
\text { which help to manage the condition of halitosis? }\end{array}$ & 275(90.2) & $30(9.8)$ \\
\hline 4. & $\begin{array}{l}\text { Do you visit dental clinic at least twice a year which } \\
\text { helps in prevention of halitosis and other oral } \\
\text { condition? }\end{array}$ & 265(86.9) & \\
\hline
\end{tabular}

\section{Source: primary data}

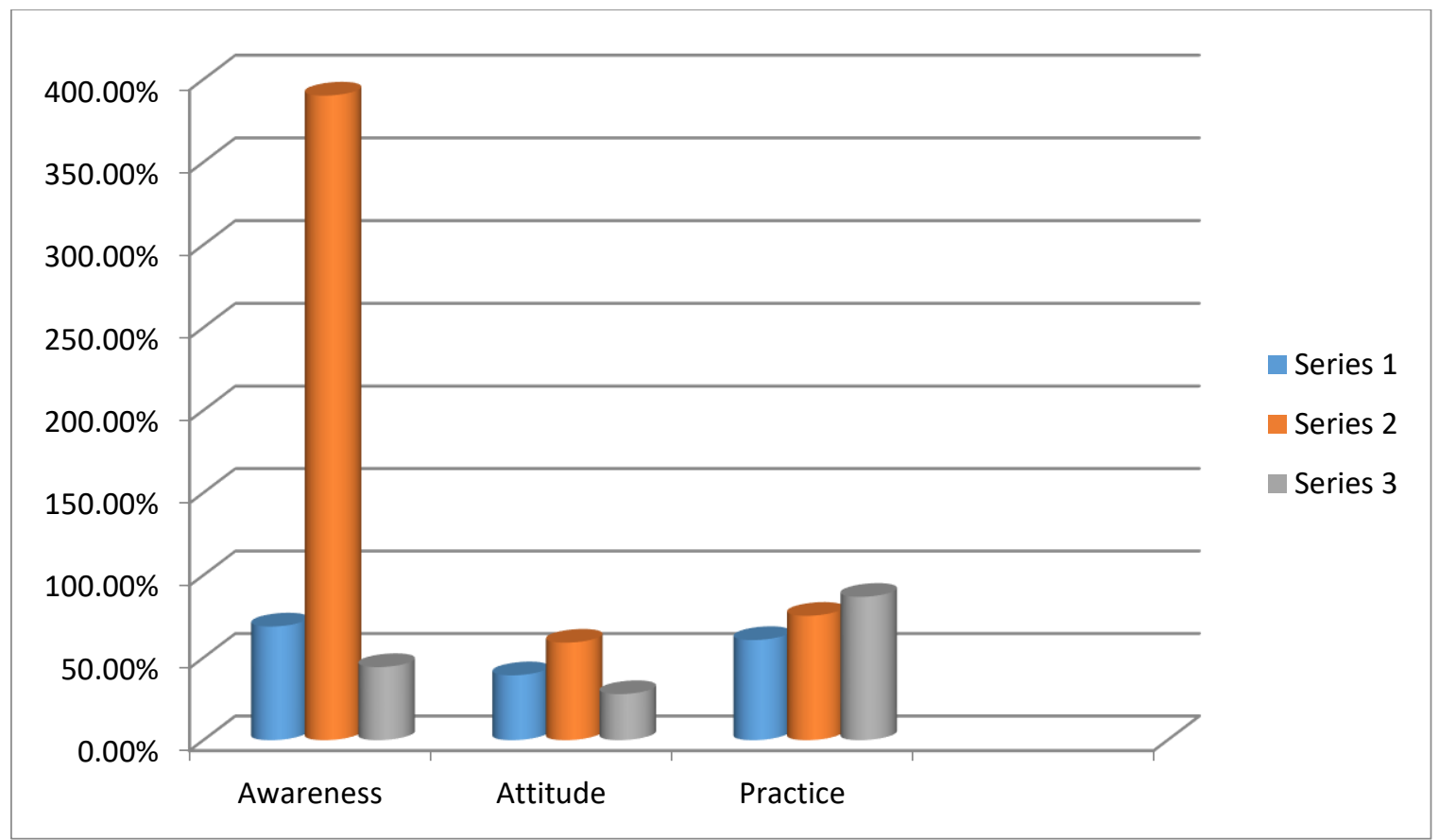

Figure 1: Histogram representing the awareness, attitude and practice of respondents towards halitosis 


\section{Discussion}

In this study, it was revealed that majority of the respondents where females with $62.3 \%$ while males accounted for $37.7 \%$. On the age of the respondents, those within the age bracket of 18 22 years were the majority with $57.4 \%, 23-27$ years accounted for $36.1 \%$, while those in the age bracket of 28-32years accounted for $6.5 \%$ of the respondents. The results further depicts that majority of the respondents were single with $88.5 \%$ while only $11.5 \%$ were married. Also on the level of education, the table depicts that $39.3 \%$ of the respondents had a diploma, $34.4 \%$ were certificate holders while HND holders accounted for $26.3 \%$ of the respondents. The greater participation of females in the study can be attributed to the fact that the community health department comprises of more females as certain course were reserved to the female gender. This study findings was in conformity with a similar study conducted in Tanzania which reported that out of a total of 785 secondary school students, females accounted for the larger percentage with $(50.3 \%)$ than the males (49.8\%).the study revealed that majority of the respondents were single, this can be explained if we consider that the larger respondents was from the age bracket 1122 years. most of the courses offered in various departments were diplomas thus explain why the study reported the dominance of diploma holders in the study. However not all departments offer HND courses as such buttressing the point why it accounted for the least respondents.

The study findings further reveals that majority of the respondents were aware of the condition with $68.9 \%$ while $31.1 \%$ were not aware of the condition halitosis. Also a larger percentage of the respondents are aware that unclean teeth can cause halitosis which in turn can lead to social and psychological problems as accounted by $90.2 \%$ of the respondents. On the awareness on other illness that can lead to halitosis, 55.7\% denied having knowledge on any of these illness while $44.3 \%$ ascertained having knowledge on the illness. It clearly depicts that the respondents were aware of the condition halitosis as well as its causes. This can be justified with the level of education of the respondents' majority being diploma holders. Previous studies have shown that education has a direct relationship with the health seeking behaviors of individuals, this is more so with respect to the girl child as education has been found to positively impact on their health seeking behaviors.

Furthermore, the study also revealed that $60.7 \%$ of the respondents do not isolate people with halitosis, while $39.3 \%$ ascertained that they find it difficult to associate with people suffering from the condition. Also a large percentage do not feel comfortable when they do not brush their teeth in the morning while $59.1 \%$ of the respondents confirmed that they are comfortable with themselves even without brushing their teeth in the morning. Also the table further reveals that majority have never experienced any oral abnormality while 27.9 had experienced different abnormalities at one time in their lives. According to Cooper, 2002; Ajala, 2005, knowing that it is necessary to brush your teeth once or twice daily and actually doing it are two different things completely. In other words people may be aware of the Dental ills that are associated with bad oral hygiene and yet fail to maintain it. The good attitude shown towards good oral hygiene by the respondents can be attributed to the level of education of majority of the respondents with the least being a certificate holder.

The study also revealed that $60.7 \%$ of the respondents do take substances that cause bad breath, the study identified such substances as onions, garlic while some of them were smokers. $39.3 \%$ 
denied the intake of substances that cause bad breath. On the use of substances to manage the condition, majority $75.4 \%$ confirmed the use of substances while a small portion use not substances to manage the condition. Also the table depicts that a large percentage of the respondents $90.2 \%$ do brush their teeth twice daily while only $9.8 \%$ denied the brushing of teeth twice daily. The result also reveals that only a small portion of the respondents $13.1 \%$ do no visit a dentist at least twice a year. Lack of oral hygiene practices has been identified as a possible predisposing factor of halitosis (Barenes 2001). As reported by ADHA 2006, brushing twice daily, flossing, use of dental sealants, dental visit and use of mouth washes etc, are essential practices towards prevention of halitosis as well as improvements in the health of teeth and gums of individuals. From the study findings, we can relate the use of substances to prevent halitosis due to the perceived use of mouth odour causing substances by majority of the respondents. This also prompt the respondents to brushing at least twice daily to prevent the condition, some of the respondents in addition to the use of toothpaste also use the traditional Miswak to clean their teeth's. This practice has greatly contributed in the elimination of millions of bacteria that cling to the corrugated part of the tongue particularly on the back side and are the causes of unpleasant smell.

\section{Conclusion}

Women were identified to constitute a larger percentage of the respondents with Majority being aware of the problem of halitosis as a dental issue which in turn can lead to social and psychological problems.

Also a few of the respondents do isolate person suffering from bad breath, however majority reported that as students, they were always uncomfortable interacting with people any time they forget to brush their teeth.

Even though a larger percentage of the respondents do take substances that can cause bad breath, they engage in preventive measures like chewing substances like gums and Miswak that can eliminate the odour and brushing twice daily in addition to visiting a dentist at least twice in a year.

\section{Acknowledgement}

The authors would like to acknowledge everyone who has contributed to the success of this work. We express our appreciation to the authorities and Ethical Review Committee of college of health sciences, students and staffs for their immense contributions.

\section{Consent}

As per international standard or university standard, respondent's written consent has been collected and preserved by the author(s)

\section{Ethical Approval}


As per international standard or university standard, written approval of Ethics committee has been collected and preserved by the author(s).

\section{Competing Interests}

Authors have declared that no competing interests exist.

\section{References}

[1] Ajala, J. A. (2005). HEALTH EDUCATION IN WELLNESS AND SICKNESS- This day, University of Ibadan,Pp. $17-23$.

[2] Ashrin N. (2007). "SELF-ASSESSMENT OF HALITOSIS AMONG DIABETIC SAUDI FEMALE PATIENTS". Journal of the Egyptian Dental Association 53(1.2)

[3] Asiya Ali Faki (2012). SOME ABNORMAL MOUTH CONDITION.pg 1

[4] Cortelli J.R, Barbosa M.D, Westphal M.A (2008) "HALITOSIS. A REVIEW OF ASSOCIATED FACTORS AND THERAPEUTIC APPROACH". Brazilian oral research journal 22(1) 44-45

[5] Eli I, Baht R, Koriat H, Rosenberg M, (2001); "SELF-PERCEPTION OF BREATH ODOR". Journal of the American dental association, 132(5); 621-626.

[6] Elias MS, ferriani MG (2006). "HISTORICAL AND SOCIAL ASPECTS OF HALITOSIS" Rev Lat Am Enfemagem, 14(5):821-823

[7] Eggert and Michael (2012); "Bad Breath Is An Ancient Concern" Archived article.

[8] Kapoor U, Sharma G, Juneja M, Nagpal A (2016). "HALITOSIS: CURRENT CONCEPTS ON ETIOLOGY, DIAGNOSIS AND MANAGEMENT" European journal of dentistry. 10 (2) 292-300

[9] Krespi YP, Shrime MG, Kackera (2006). "THE RELATIONSHIP BETWEEN ORAL MALODOR AND VOLATILE SULFUR COMPOUND PRODUCING BACTERIA" Otolaryngology Head Neck and Surg. 135(5): 621-626

[10] Quirynen M, van den Velde S, Vandekerckhove B, Dadamio J (2012); "ORAL MALODOR. IN NEWMAN MG, CARRANZAS CLINICAL PERIODONTOLOGY” (1 $11^{\text {th }}$ ed) ISBN 978-1-43770416-7

[11] Sanz M, Roldan S, Herrera D. (2001). "FUNDAMENTALS OF BREATH MALODOR" journal of contemporary Dental practice. 15:2(4)1-7

[12] Shipman A, Orenbuch S, Rosenberg M. (2002). "BAD BREATH [+ or -] A MAJOR DISABILITY ACCORDING TO THE TALMUD" IMAJ, 4:843-845

[13] Scully C (2008). "PERIODONTAL" Journal of the American dental association, 48: 66-75

*Corresponding author.

E-mail address: harunsambo@yahoo.com 